\title{
Title: A meta-ethnography of organisational culture in primary care medical practice
}

\begin{abstract}
Purpose - Over the past decade, there has been growing international interest in shaping local organisational cultures in primary care. However, the contextual relevance of extant culture assessment instruments to the primary care context has been questioned. The aim of this paper is to derive a new contextually appropriate understanding of the key dimensions of primary care medical practice organisational culture and their interrelationships.

Design/methodology/approach - A systematic search of six electronic databases followed by a synthesis of published qualitative research using techniques of meta-ethnography including translation and re-interpretation.

Findings - Sixteen papers were included in the meta-ethnography. They derived from studies conducted in the UK, US, Canada, Australia and New Zealand, and fell into two related groups: (1) those focused on practice organisational characteristics and narratives of practice individuality, and (2) those focused on sub-practice variation across professional, managerial and administrative lines. Our synthesis indicates that primary care organisational culture was characterised by 4 key dimensions: responsiveness, team hierarchy, care philosophy and communication. These dimensions are multi-level and inter-professional in nature, spanning both practice and sub-practice levels.

Research limitations/implications - Our synthesis contributes to organisational culture theory development by newly identifying four key cultural dimensions. These dimensions provide a conceptual framework that will enable researchers to evaluate and understand both cultural and sub-cultural levels in primary care.

Practical implications - The synthesised cultural dimensions present a framework for practitioners to understand and change organisational culture in primary care teams.

Originality/value - The use of meta-ethnographic techniques to investigate issues of organisational culture is innovative, and this synthesis is one of the first attempts to systematically develop a qualitative conceptual framing of primary care organisational culture.
\end{abstract}

Keywords: meta-ethnography; primary care; organisational culture

\section{Introduction}

Since the 1980s, there has been growing international interest in understanding local organisational cultures in healthcare, and in shaping them via new financial and organisational arrangements in order to support quality and safety improvement (Mannion et al. 2009). In the UK, US, Canada, Australia and New Zealand in particular, the management of organisational culture has become increasingly recognised as a necessary part of primary healthcare reform. Within these countries, culture has been perceived as open to manipulation to suit wider policy objectives (Scott et al. 2003a,b,c), with policy makers and managers designing a mix of strategies including financial incentives and primary care practice redesign to influence the formation of 'high quality' cultures (Campbell et al. 2000; Davies 2002; Mannion et al. 2007) that promote access, clinical effectiveness, interpersonal effectiveness, equity and efficiency (Department of Health 2000; General Practice Strategy Review Group 1998; Institute of Medicine 1999; Medicare Australia 2006; New Zealand Ministry of Health 2006). As healthcare policy 
internationally has increasingly focussed on interprofessional teamwork as a means of improving chronic disease management and other aspects of quality and safety through interprofessional teamwork (e.g. Department of Health 2003; Institute of Medicine 2001), the importance of understanding the ways in which local practice cultures mediate the quality and delivery of care has increased.

Organisational culture can be defined as 'a shared set of norms and behavioural expectations characterising a corporate identity' (Grindle 1997). The norms and expectations are reinforced through shared 'rituals'. The existing literature on primary care medical practice culture is limited (Smith \& Webster 2009), with the majority of extant studies focussing on the quantitative measurement of specific aspects of practice culture over a large number of practices and investigating their association with outcomes such as team functioning and morale (Hann et al. 2007; Poulton \& West 1999), or aspects of quality of care (Bower et al. 2003; Shortell et al. 2000).

While understanding and measurement are described as prerequisites for any effective decision to change the culture of a healthcare organisation (Mannion et al. 2009), the contextual relevance of extant instruments has also been questioned. In particular, Scott et al. (2003a) claim that sub-cultural diversity within healthcare organisations is often overlooked in favour of organisational-level assessments of cultural characteristics. The Competing Values Framework (CVF) instrument, for example, in which respondents distribute 100 points across four sets of statements according to the descriptions that best fit their organisation, reflects the fact that no organisation exhibits only one culture or set of values. Rather, multiple cultures and values coexist simultaneously. Studies that have employed the CVF in primary care have characterised practices as predominantly 'clan'type cultures associated with 'family-like' internal cohesion, a strong sense of history and tradition, and a strong orientation towards professional autonomy and paternalistic leadership styles (Hann et al. 2007; Marshall et al. 2003). Scott et al. (2003a), however, write that this organisational-level approach is too simplistic as sub-cultures can often attenuate healthcare culture change programmes in complex ways (see also Child \& Faulkner 1998).

Schein (1985) describes organisational culture as comprising a series of 'levels' that intersect with broader societal culture, organisational structures, and organisational subgroups. Thus, within any healthcare system, organisational culture may vary considerably both across and within individual organisational units. Healthcare teams have been described as highly 'tribal' as they contain a range of professional, administrative, and managerial sub-cultures (Scott et al. 2003b). This view is supported by much qualitative research, which emphasises the predominance of clinical hierarchies and professional boundaries within primary care medical practice teams (Nancarrow \& Borthwick 2005). Poulton \& West (1999), for example, report on the problematic nature of teamwork in primary care due to the hierarchical organisation of practices, with doctors as team leaders and employers of the other practice staff (Wilson 2000). The existing hierarchical, inward-looking nature of primary care medical practices has the potential to conflict with the demands of recent international healthcare policy reforms described above that have focussed on reducing inter-practice variation and increasing interprofessional teamwork.

All this suggests that a more nuanced understanding of primary care culture is required, especially if we want to understand the ways in which local practice cultures mediate the quality and delivery of care. It is important not only to initially identify the key 
dimensions of primary care medical practice culture, but also the multi-level cultural complexities that can lie within.

The aim of this review is to identify the key dimensions of primary care medical practice culture on which practices might vary and the interrelationships between these. The review draws on existing qualitative research across five countries that vary in terms of policy and primary care systems - the UK, US, Canada, Australia and New Zealand. Our aim is reflected in our choice of synthesis method, meta-ethnography, as developed by Noblit \& Hare (1988). As the most conceptually and practically-developed method for synthesising qualitative research (e.g. Britten et al. 2002; Campbell et al. 2003; Malpass et al. 2009), meta-ethnography was employed as it allows for the development of new insights based on the innovative integration of existing studies. This paper begins with an overview of extant theoretical, empirical and policy-focussed writings on organisational culture in primary care medical practice. We then describe the systematic literature search process before reporting on a 'reciprocal translation' and 'line-of-argument' synthesis of 16 papers.

\section{Methods}

The review had four stages: (1) systematic literature search; (2) critical appraisal; (3) data extraction; (4) synthesis using techniques of meta-ethnography, as originally described by Noblit and Hare (1988).

\section{Systematic literature search}

\section{Formulating the research question}

Guided by the Setting Perspective Intervention Comparison Evaluation Social Science Method) (SPICE(S)) tool (Malpass et al. 2009), we searched for qualitative literature on organisational culture in primary care medical practice. The final guiding definition for the meta-ethnography was 'qualitative empirical published journal articles focussing on characteristics of primary care medical practice culture'.

\section{Data sources and search strategy}

The search strategy combined a systematic search of six bibliographic databases (Medline, AMED, British Nursing Index and Archive, PsychINFO, SSCI and CINAHL) and a cited reference search.

It is well documented that the retrieval of relevant papers for the systematic reviewing of qualitative research is complex. We therefore replicated an existing strategy developed by Shaw et al. (2004) based on thesaurus terms, free-text terms, and broad-based terms to maximise sensitivity and recall. Initial scoping exercises were conducted in a small number of databases to refine the search terms. In order to capture international literature, the term 'primary care' was expanded to incorporate other widely-used international variants. During a preliminary cited reference search it became apparent that the term 'organisational culture' was predominantly employed within quantitative studies. Based on the initial scoping exercise, we expanded this term to capture as broad a range as possible of relevant qualitative research on this topic. Finally, we used an existing CINAHL qualitative expert search to maximise the sensitivity of the methodological component of our search. The final search terms were combined using the Boolean logic 
terms 'and' and 'or'. Further details of the search are available from the authors on request.

\section{Identifying relevant papers: the screening process}

The retrieved records were exported to Refworks online reference manager software to facilitate their organisation, storage and screening. The inclusion criteria were that the paper should employ at least one form of qualitative methodology to investigate organisational culture in at least one primary care medical practice. Exclusion criteria were papers not written in English, non-research papers, and papers that were not published in accessible peer-reviewed journals. SG reviewed the titles, abstracts and full text against the inclusion and exclusion criteria in discussion with the rest of the team. No limit on publication date was used and authors were not contacted. The screening process is summarised in Figure 1.

Figure 1 here.

\section{Critical appraisal}

The final stage of the screening process was a critical evaluation of the remaining papers. The appraisal of qualitative research has generated considerable debate concerning the appropriateness and indeed feasibility of such an evaluation (Mays \& Pope 2000). However, provided the quality criteria are made explicit, the appraisal of studies can be a valuable a part of the selection process, as the inclusion of poorly designed and executed studies could render the basis on which the secondary interpretation is formulated questionable. A critical appraisal of the remaining 41 papers was therefore conducted using the Critical Appraisal Skills Programme (CASP) tool. The CASP tool was selected as it is more explicit than other tools regarding the appraiser's reasons for making particular quality judgements, and it has also been successfully employed in previous meta-ethnographies (Campbell et al. 2003; Malpass et al. 2009).

\section{Sampling of papers}

Following the critical appraisal and inclusion of three additional papers identified through a cited reference search, 28 papers remained. While the number of papers synthesised in a meta-ethnography varies greatly across studies, we decided that 28 papers was too many to effectively synthesise using meta-ethnography. The purposive sampling of papers is common in meta-ethnography, albeit not always grounded in a prior systematic search (Britten et al. 2002). While there was some overlap across the papers, they were organised according to their primary thematic focus then grouped under six headings: teamwork; practice uniqueness and variation; workload; clinical hierarchies; professional boundaries; and interprofessional communication. Three papers were then purposively sampled from each theme. Where more than three papers addressed the same theme, measured quality from the critical appraisal was taken into account, and papers with the lowest scores were excluded. For the themes containing less than three papers ('clinicalmanagerial boundaries' and 'communication'), both papers were judged high quality and were included. The final purposive sample of papers to be synthesised was 16 (Appendix A).

The synthesis

Determining how the studies are related and identifying second order constructs 
SG read all the papers, extracted key themes and concepts, and synthesised the findings in discussion with the rest of the team. This was done through a process of 'reciprocal translation' to identify where themes and concepts from the set of papers converged ('congruent synthesis') or diverged ('refutational synthesis'), before synthesising these concepts in a final reconceptualisation of findings across studies ('line-of-argument synthesis'). Preliminary synthesis involved reading and re-reading the papers and the extracted findings to consolidate thematic and conceptual understandings and their interrelationship both within and between studies. A table was then compiled in which authors' interpretations or 'second order constructs' from each paper were noted in one column. Authors' descriptions of the meaning and illustrative quotes from the original papers ('first order constructs') were noted in a second column so that they could be examined and compared. 26 second order constructs were identified in total and are presented in Table 1, along with the papers that refer to that construct. In a third column, additional ideas were noted as they arose. These ideas fed into the development of potential third order constructs. Conceptual maps were drawn for key second order constructs for each paper in order to preserve their contextual integrity (Britten et al. 2002).

\section{Table 1 here}

\section{Translating studies into one another and synthesising translations}

Once all 16 papers had been entered into the table, it was possible to conduct a 'reciprocal translation' followed by a 'reciprocal synthesis' of the second order constructs within each of the six thematic groupings outlined above. At an early stage in the metaethnography, we discerned two groups of papers with differing conceptual foci: group 1 focussed on practice-level cultural variation and group 2 focussed on professional and managerial sub-cultures within practices. Papers in groups 1 and 2 were initially synthesised separately using the 'reciprocal' approach, with individual papers referenced using the numbers employed in Table 1. Although the papers had been classified according to six primary thematic groupings during the initial selection process, the majority overlapped across a range of secondary themes and this is reflected in the results section of this review. The 'reciprocal synthesis' then initiated the development of a 'line of argument' synthesis because each of the papers focussed on complementary aspects of primary care medical practice culture that could be usefully brought together to construct a broader conceptual model. There were no cases of concepts being strongly contested across papers.

\section{Findings}

\section{Reciprocal synthesis of group 1 papers: Practice-level cultures}

This group of papers focussed on practice organisational characteristics and narratives of uniqueness and autonomy.

\section{Practice organisational characteristics}

A key feature of organisational variation was practice size, including both practice team size and patient list size (Papers 6, 8, 11, 12, 16). Practice team composition varied across national contexts, but typically included doctors, healthcare staff (including nurses, pharmacists, healthcare assistants, etc.), managerial staff (including practice managers), and administrative staff (including receptionists and secretaries). In seven of the papers 
synthesised (Papers 2, 6, 7, 8, 11, 12, 14), variation in practice team size was linked to variation in practice spatial and temporal organisation, and the impact of these factors on interprofessional communication. In larger practice teams or 'group practices' (Paper 7) ( $>6$ doctors, $>8,000$ patients) (Paper 16) where increasing numbers of doctors and nurses preferred to work on a part-time basis (Papers 12, 15), inter-professional communication was found to be more complex (Paper 2) and fragmented (Paper 12) than in smaller teams ( $>4$ doctors, $<3,000$ patients) $(7,16)$. Such 'fragmentation' (Paper 5) was augmented by large, modern practice buildings (Paper 12) where individuals were separated in profession-specific silos (Papers 4, 12) within 'large, functionally differentiated spaces' (Paper 11). This augmented internal hierarchies (Paper 16) and limited interprofessional collaboration (Papers 4, 5, 15). Paper 2 identified the development of two separate professional 'silos': 'the frantic bubble' (doctors) and 'the flexible team' (nurses and administrative staff). Formal meetings were important within this context to ensure that effective interprofessional collaboration could take place (Papers 2, 4, 7, 14, 15).

'Open communication' (Papers 1, 2, 4, 14) was characteristic of informal everyday faceto-face communication and collaboration that took place within shared workspaces (Paper 12), during coffee-room meetings (Paper 8), lunch breaks (Paper 12), in hallways (Papers 2, 12), reception areas (Paper 12), open areas (e.g. utility or supply rooms), and between scheduled patient appointments via telephone or IT systems (Papers 2, 7, 12). Informal communication was framed positively and characterised by spatial proximity alongside inter-professional approachability, availability and flexibility. According to doctors, nurses and practice staff, it was also the preferred and most effective method of communication within practices (Paper 10), contributing to a more egalitarian (Paper 16) and trusting practice culture (Paper 1, 5, 14, 16) with greater continuity of care (Paper 7) and professional work satisfaction (Paper 7). One study (Paper 1) found that smaller practices had more shared spaces and therefore more opportunities for informal communication. However, most of the studies found that practices of all sizes combined both formal and informal communication irrespective of size but on a sliding scale, with the former becoming increasingly necessary as practice teams increased in size and scope of chronic disease management work.

\section{Practice narratives of uniqueness}

Four papers in this group focussed on how practices made sense of quality improvement initiatives intended to reduce practice-level variation through chronic disease management and interprofessional teamwork (Papers 6, 8, 11, 16). A key feature of these papers was the authors' descriptions of practices as unique, individualistic, 'characterdriven enterprises' (Paper 4), with doctors as leaders (Paper 10) who drove the dominant practice narratives regarding the history, traditions, and identity of the practice (e.g. 'community-oriented practice', 'mechanistic and profitable practice' (Paper 11)) in ways that often diverged from those of policymakers.

Practice narratives of uniqueness and autonomy were framed in terms of both the internal organisational features described above and the more external features of practice location (i.e. urban, suburban or rural) (Papers 1, 6, 8, 9, 12), whether the area was affluent or deprived (Papers 6, 7, 8)), and the size and characteristics of the patient population (Papers 12, 16). For example, in Paper 8, each practice 'made sense' of a major UK pay-for-performance programme by developing a dominant practice 'story' that drew on one or more of four dominant strands of discourse regarding UK primary 
care values to describe their ongoing approach to patient care. These were the 'holistic' strand, the 'public health' strand, the 'primary care medical practice as business' strand, and the 'primary care medical practice as a modern, accountable, high quality service' strand. These 'stories' were variously framed in terms of innovation and resistance to change, as well as the history, values, and future direction of the practice. While they were partly based on the organisational characteristics of the practice, this relationship is not linear as practices were also described as places where 'small changes lead to large effects and large changes lead to small effects' (Paper 11). Thus, rather than quality improvement initiatives having the same effect across all practices, practices are 'complex adaptive systems' (Paper 11) that undergo a 'non-linear' process of 'organisational 'reinvention' and 'improvisational change' that is driven by particular combination of a range of factors.

\section{Reciprocal synthesis of group 2 papers: Sub-cultures within practices}

This group of papers considered sub-practice variation within practices across clinical, managerial and administrative boundaries.

Professional sub-cultures: the doctor-nurse clinical hierarchy and interprofessional teamwork

Professional differences between doctors and nurses were framed in terms of their distinct 'philosophies and histor[ies]' (Paper 10) and were perceived as a barrier to effective collaborative working (Papers 10,13). While not universal, some authors argued that it was possible for doctors and nurses to develop a 'collaborative culture' (Paper 13) of 'relational coordination' (Paper 4) provided there were clear goals, externally measurable outcomes (Papers 4, 7), effective administrative and IT systems (Paper 7), shared values, and a collectively recognised practice-level identity. In particular, the 'effective delegation' (Paper 16) of clinical work by doctors to nurses depended on doctors having trust, respect and confidence in nurses' abilities (Papers 1, 4, 13). All of these factors were underpinned by effective interprofessional communication (Papers 1, 4, 7, 13, 14, 16) in which mutual demands needed to be framed in 'the appropriate manner at [the] appropriate time' (Paper 1).

In seven of the papers, effective teamwork was reported as frequently challenged by everyday behaviours and attitudes that accentuated internal hierarchies and intensified the boundary between doctor and nursing sub-cultures (Papers 1, 4, 5, 10, 12, 13, 15). A 'common culture' (Paper 4) that inhibited teamwork within practices was the longstanding predominance of a 'physician-centred culture pattern' (Paper 4) based on a 'traditional power structure' (Paper 5) or 'clinical hierarchy' (Papers 3, 15), with doctors as leaders, medical specialists (Papers 5, 10, 13) and employers (Paper 4), and nurses as their less specialised employees (Papers 13, 15) focussed on 'care' rather than 'biomedical cure' (Paper 1). The hierarchy between doctors and nurses accentuated the 'uni-professional' (Paper 5) nature of professional development, resulting in 'ineffective communication', with doctors and nurses working in separate 'silos' (Paper 4) or 'subdomains' (Paper 3) based on clearly defined professional roles (Paper 4) and poor communication that impeded mutual understanding (Paper 15). Paper 10, for example, found that while all practice team members were able to discuss their own role with ease, most described their colleagues' roles in a 'task-oriented reductionist manner'. Such misunderstanding was compounded by a 'culture of busyness' (Paper 12), in which time 
pressures presented a significant constraint on interprofessional working and understanding.

The nature of practice funding models was also found to impact in the nature of interprofessional collaboration across all five countries included in the synthesis. For example, in Paper 7, the US fee-for-service funding model incentivised higher-paid doctors to perform tasks that could be delegated to lower paid medical assistants as practices did not receive external payment for work carried out by the latter. In contrast, in New Zealand, teamwork was promoted when practices, not individual practitioners, were bulk-funded for capitated healthcare provision (Paper 14). Salaried practices, where doctors and nurses alike were employees, were also considered to be particularly supportive of effective teamwork between doctors and nurses (Paper 14). Within the UK (Papers 3, 5, 6, 8, 9, 15, 16), pay-for-performance was increasingly employed by Primary Care Organisations to incentivise doctors to delegate routine, protocol-driven chronic disease management work to nurses and healthcare assistants.

\section{Professional and managerial sub-cultures: the biomedicalised workload and internal managerial teams}

Five papers describe recent managerial trends within UK (Papers 3, 6, 8), US (Paper 4) and New Zealand (Papers 13, 14) healthcare as representing a significant break from previous bureaucratic governance arrangements by exposing practices to new forms of performance measurement, management and audit. In the USA (Paper 11), the 'coevolving professional world of the health system and payer manager [had] been increasingly interacting with the physician professional value system', resulting in practice work becoming increasingly 'biomedicalised' (Paper 3) in favour of single disease-focussed 'chronic disease management' (Papers 3, 5, 9). In the UK, new 'hierarchies of appropriateness' (Paper 3) had evolved for clinical work, resulting in chronic diseases being managed in separate professional 'silos' (Papers 7, 9), with 'complex specialist' work retained by doctors (Papers 5, 6), and 'routine protocol-driven tasks' delegated to nurses by doctors (Papers 3, 5, 7, 9).

In the UK and New Zealand, doctors' holistic, patient-centred care (the 'traditional, biographically-framed family doctor') (Paper 3) was described as becoming 'eroded' (Papers 9,14) in favour of a new professional identity ('the biomedical specialist' (Paper 3)) based on the management of particular chronic diseases (e.g. asthma, diabetes, coronary heart disease). Other studies found that doctors and nurses employed 'holism' and 'biomedicine' to rhetorically construct their own professional boundaries (Papers 6, 13). Thus, doctors in the UK and New Zealand increasingly viewed themselves as specialists in generalist holistic care (Paper 13) due to their 'overall responsibility' (Paper 6) for their patients. Practice nurses also described themselves as biomedical specialists in chronic disease management as they were responsible for the 'overall' holistic care of patients' chronic conditions due to the increased time they spent with patients in chronic disease management clinics (Paper 6).

Five papers (Papers 4, 5, 6, 8, 13) reported a trend towards a 'concentration of authority within practices' (Paper 6) within the UK, although this was 'inconsistent and varied' (Paper 13). Managerial decision-making and monitoring was being led by new 'internal teams' of clinical and managerial staff who were responsible for making the major organisational decisions, monitoring practice progress for targets, and 'chasing up' other team members who were failing to perform adequately (Papers 6, 8). This had resulted in 
a reportedly 'new form of internal regulation', with key clinical staff developing increased managerial responsibility over their clinical colleagues and key administrative staff developing increased managerial responsibility for clinical domains of the contract (Paper 6). However, this new managerial hierarchy was found not to replace, but to augment more enduring clinical hierarchies within practices (Papers 4, 5).

\section{'Line of argument' synthesis}

Having conducted the reciprocal syntheses of the two groups of papers, we considered the final stage of the meta-ethnography, where the two groups of papers were brought together to construct a final 'line of argument'. Figure 2 illustrates our final synthesis of the 16 papers as comprising four key dimensions of culture. The anchors for these dimensions were: internal vs. external responsiveness; hierarchical vs. egalitarian structure; biomedical vs. holistic focus of care; and coherent vs. fragmented communication. Practices and professional, managerial and administrative sub-cultures therein will stress varying proclivities towards each of these eight characteristics over time, with each pair of characteristics co-existing in constant tension. Table 2 illustrates the characteristics of practice and sub-practice responses across these four dimensions.

\section{Figure 2 here}

\section{Table 2 here}

The first dimension concerns the way in which practices as individualistic, autonomous, personality-driven organisations respond to external and internally-based concerns. An externally-responsive practice culture will focus on managerial, business and public health initiatives instigated by local healthcare organisations such as pay-for performance chronic disease management initiatives as well as the performance of other practices. An internally-responsive culture values individual practice-level autonomy and is highly responsive to issues that impact on the internal trust and collegiality of the team. Whether the managerial and administrative sub-cultures are externally or internally-focussed will often depend on the focus of the practice, and of the dominant clinical sub-culture in particular.

The second dimension concerns relationships of hierarchy and egalitarianism at practice and sub-practice levels. At practice level, a new egalitarian team culture has emerged following recent international policy initiatives to increase interprofessional teamwork premised on inter-professional trust and respect. At the same time, hierarchical subcultures continue to exist based on the dominance of doctors over nurses within the clinical sub-culture, and the dominance of doctors over the managerial and administrative sub-cultures based on their status as employers. New hierarchies are also emerging within nursing teams between nurses and less-qualified healthcare assistants based on a new biomedically-driven distribution of clinical work based on skill and cost-effectiveness. Finally, new managerial work is also creating a new culture of managerialism, with interprofessional hierarchies that crosscut existing clinical, managerial and administrative sub-cultures.

The third dimension concerns a practice's approach to patient care. A biomedicallyfocussed culture employs a managerially efficient, disease-focussed approach to care. Patients are categorised according to pathological complexity and clinical work is distributed hierarchically according to expertise for maximum efficiency and cost 
effectiveness. A holistic culture will emphasise a person-centred approach to care, with patients' narratives and the social and psychological context given value within the consultation. Clinical teams can also be more focussed towards a particular form of care depending on the overall philosophy of the practice, with this often impacting on the strength of the managerial sub-culture.

The fourth dimension concerns modes of communication within practices and across subcultures. A culture of coherent communication is characterised by spatial and temporal proximity and interprofessional trust and respect both formally and informally. A culture of fragmented communication is characterised by a lack of face-to-face communication and spatial and temporal distance across professional lines that attenuates a lack of interprofessional trust and respect.

\section{Discussion}

This systematic literature search and meta-ethnography of 16 papers has facilitated the identification of four main dimensions of primary care practice culture within the UK, US, Canada, Australia and New Zealand. The four dimensions operate in constant tension between their two anchors (internal vs. external responsiveness; hierarchical vs. egalitarian structure; biomedical vs. holistic focus of care; and coherent vs. fragmented communication). They are multi-level in nature, spanning both practice and sub-practice levels. Scott et al. (2003d) suggest that the concept of organisational culture incorporates a diverse array of phenomena, theories and methodologies and that a detailed understanding of the context of a particular organisation is of central importance if an accurate understanding and measurement of culture is to be achieved. This metaethnography, through the processes of 'reciprocal translation' and the development of a 'line-of-argument' synthesis, has gone some way towards the identification of new contextually-specific cultural dimensions in primary care that were not evident in any of the individual papers included in our study. It also supports recent calls in the literature for a shift in theoretical focus from culture as stable to culture as a dynamic entity, with greater focus on cultural, sub-cultural, and interprofessional dynamics across organisational levels.

\section{Implications for practice}

Scott et al. (2003d) write that advocates of strategic cultural change in healthcare organisations typically assume that although cultures are highly resistant to change, they are also malleable to these wider reforms. As with previous studies (Hann et al. 2007; Scott et al. 2003c), we did not find a direct link between organisational culture and performance. However, our synthesis does partly support recent studies that have found a link between practice culture, organisational structure (Curoe et al. 2003), and the mode of delivery of measured healthcare (Isaacson et al. 2009; Shortell et al. 2000). Although it is not yet possible to describe the healthcare outcomes of particular cultures, the proclivity of a practice towards a particular combination of cultural characteristics has potentially significant implications for the model of patient care delivered. For example, (a) a modern, externally-responsive team with a biomedical focus may be more geared towards externally measured care, whereas (b) a traditional, internally-responsive team with a holistic focus may provide better unmeasured care. This finding supports Scott et al.'s (2003c) conclusion that perhaps only those aspects of performance that are valued within a given culture can be enhanced. 
This study aimed to identify common practice-level cultural characteristics across five national contexts. Improving the quality of primary care has become a major issue for each of these healthcare systems, with this reflected in increasingly systematic and structured approaches to reform. Half of the studies synthesised came from the UK (8), with a smaller proportion coming from the US (3), Canada (2), Australia (1) and New Zealand (2). The fact that the majority of papers came from the UK could be explained by the fact that over the last decade (when the majority of the synthesised papers were published (14)), there has been greater investment in primary care audit and research activity there than elsewhere. The relative paucity of qualitative studies investigating primary care culture in the latter four countries makes it difficult to draw comparisons between the five countries. However, it was possible to conclude that the funding models and quality improvement initiatives employed within each country did drive the delivery of primary care work towards increasingly managerial, biomedically-driven models of care, and that there was a strong clustering of common cultural dimensions across all five countries.

Practice structure (team size and organisation) was also linked to interprofessional communication, with larger practices demonstrating increased fragmentation (Curoe et al. 2003). While this finding runs counter to recent international policy initiatives aimed at increasing both practice size and effective interprofessional teamwork (Institute of Medicine 2001), a recent study by Kaissi et al. (2007) found that the 'fit' between the culture of a practice and its organisational structure was an important factor in determining the provision of high-quality care. Thus, size may be one factor that contributes to practice performance alongside a broader range of dimensions identified in this study.

\section{Theoretical implications}

Theories of sub-cultures (Child \& Faulkner 1998; Jordan 1994; Martin \& Seihl 1983; Scott et al. 2003b) strongly guided our thinking in this study. In particular, Jordan (1994) proposes that organisational culture should be perceived as an interwoven web of subcultures that combines individual and aggregate cultural properties and these may coincide with or diverge from any overall organisational culture. These theories served to validate our developing conceptualisation of culture and fed into the development of the final stage of the synthesis. While many of the cultural characteristics identified in this study have been described in previous studies using instruments such as the CVF (Hann et al. 2007; Marshall et al. 2003), we found that individual practice cultures comprise potentially highly variable combinations of the eight cultural characteristics identified that intersect at both practice and sub-practice levels as well as across professional groups (Figure 2). This combination of characteristics was not static, but changed over time and across practices and sub-cultures. In this respect, we found Erez \& Gati's (2004) multilevel model of culture as comprising structural characteristics that interact across different organisation levels useful, as our synthesis demonstrated interrelationships across a range of cultural levels that were not just organisationally-dependent (Martin \& Seihl 1983) or professionally-based, but that crosscut practices as well as professional boundaries and hierarchies.

The strong degree of variation across practice cultures and sub-cultures was mainly due to the autonomous and highly individualistic nature of practices and doctors as a professional group. While an earlier study identified a reduction in important elements of 
doctors' professional autonomy as a result of increased performance management (Marjoribanks \& Lewis 2003), this review showed that doctors' autonomy was only compromised in specific areas of measured care and strongly defended in other unmeasured areas. The range of practice-level narratives of identity reflected this autonomy.

The papers synthesised were interview and observation-based studies that were both theoretical and descriptive in nature. As the quality of any synthesis crucially depends on the quality of included research, there was rich ground for further 'third order' theorybuilding due to the abundance of 'second order' interpretations (or 'underlying assumptions' (Schein 1985)) by the authors of the identified papers. It is for this reason, and also in keeping within the original framework of meta-ethnography (Noblit \& Hare 1988), that we decided against the inclusion of authors' primary 'first order' data in our findings. However, we also recognise the epistemological issues inherent in distinguishing between empirical data and author- constructed findings, as well as bringing together data grounded in different disciplinary, theoretical or methodological perspectives (Sandelowski et al. 1997).

\section{Conclusion}

Our synthesis has gone some way towards a reconceptualisation of the key dimensions of primary medical practice culture, and greater understanding of the multi-level and inter-professional nature of these dimensions across practice and sub-practice levels within the UK, US, Canada, Australia and New Zealand. However, further in-depth empirical research is required if we are to achieve a detailed understanding of the processes by which the different cultural characteristics emerge and the longitudinal inter-relationship between cultural and sub-cultural levels.

\section{References}

Bower, P., Campbell, S., Bojke, C. \& Sibbald, B. (2003) “Team structure, team climate and the quality of care in primary care: an observational study", Quality and Safety in Health Care, Vol. 12, pp. 273-279.

Britten, N., Campbell, R., Pope, C., Donovan, J., Morgan, M. \& Pill, R. (2002) "Using meta ethnography to synthesise qualitative research: a worked example”, Journal of Health Services Research Policy, Vol. 7 No. 4, pp. 209-215.

Campbell, R. Pound, P., Pope, C., Britten, N., Pill, R., Morgan, M. \& Donovan, J. (2003) "Evaluating meta-ethnography: a synthesis of qualitative research on lay experiences of diabetes and diabetes care”, Social Science \& Medicine, Vol. 56, pp. 671-684.

Campbell, S.M., Roland, M.O. \& Buetow, S. (2000) “Defining quality of care”, Social Science \& Medicine, Vol. 51, pp. 1611-25.

Child, J., \& Faulkner, D. (1998) Strategies of co-operation: managing alliances, networks and joint ventures. Oxford: OUP. 
Curoe, A., Kralewski, J. \& Kaissi, A. (2003) "Assessing the cultures of medical group practices”, Journal of the American Board of Family Practice, Vol. 16, pp. 394-8.

Davies, H.T.O. (2002) "Understanding organizational culture in reforming the National Health Service”, Journal of the Royal Society of Medicine, Vol. 95, pp. 1-3.

Department of Health (2000) Shifting the balance of power within the NHS: securing delivery. London.

Department of Health/NHS Confederation (2003) Investing in general practice - the new general medical services contract. London: Department of Health.

Grindle, M.S. (1997) "Divergent cultures? When public organizations perform well in developing countries”, World Development, Vol. 25 No. 4, pp. 481-95.

Hann, M., Bower, P., Campbell, S., Marshall, M. \& Reeves, D. (2007) “The association between culture, climate and quality of care in primary health care teams”, Family Practice, Vol. 24, pp. 323-329.

Institute of Medicine (1999) To err is human: building a safer health system. Washington DC: National Academy Press.

Institute of Medicine (2001) Crossing the quality chasm: a new health system for the 21st century. Washington DC: National Academy Press.

Jordan, A.T. (1994) “Organizational Culture: The Anthropological Approach”, National Association for the Practice of Anthropology Bulletin, Vol. 14 No. 1, pp. 3-16.

Kaissi, A., Kralewski, J., Dowd, B. \& Heaton, A. (2007) "The effect of organizational culture and structure on medication errors in medical group practices”, Health Care Management Review, Vol. 32 No. 1, pp. 12-21.

Malpass, A., Shaw, A., Sharp, D., Walter, F., Feder, G., Ridd, M. \& Kessler, D. (2009) "'Medication career' or 'Moral career'? The two sides of managing antidepressants: a meta-ethnography of patients' experience of antidepressants”, Social Science \& Medicine, Vol. 68 No. 1, pp. 154-68.

Mannion, R., Davies, H.T.O. \& Marshall, M.N. (2005) Cultures for performance in healthcare. Maidenhead: OUP.

Mannion, R., Davies, H.T.O., Konteh, F. et al. (2007) Measuring and assessing organisational culture in the NHS (OC1), NCCSDO Report.

Mannion, R., Konteh, F.H. \& Davies, H.T.O. (2009) “Assessing organizational culture for quality and safety improvement: a national survey of tools and tool use”, Quality and Safety in Healthcare, Vol. 18, pp. 153-156. 
Marjoribanks, T. \& Lewis, J.M. (2003) "Reform and autonomy: perceptions of the Australian general practice community”, Social Science \& Medicine, Vol. 56 No. 10, pp. 2229-39.

Marshall, M.N., Mannion, R., Nelson, E. \& Davies, H.T.O. (2003) "Managing change in the culture of general practice: qualitative case studies in primary care trusts", British Medical Journal, Vol. 327, pp. 599-602.

Martin, J. \& Seihl, C. (1983) "Organizational culture and counterculture: an uneasy symbiosis”, Organizational Dynamics, Autumn, pp. 52-64.

Mays, N. \& Pope, C. (2000) "Qualitative research in healthcare: assessing quality in qualitative research”, British Medical Journal, Vol. 320, pp. 50-2.

Medicare Australia (2006) Practice incentives programme, 13 September.

Nancarrow, S.A. \& Borthwick, A.M. (2005) "Dynamic professional boundaries in the healthcare workforce”, Sociology of Health \& Illness, Vol. 27 No. 7, pp. 897-919.

New Zealand Ministry of Health (2006) Primary health care strategy, September.

Noblit, G.W. \& Hare, R.D. (1988) Meta-ethnography: synthesizing qualitative studies. London: Sage Publications.

Poulton, B.C., \& West, M.A. (1999) “The determinants of effectiveness in primary health care teams”, Journal of Interprofessional Care, Vol. 13 No. 1, pp. 7 - 18.

Sandelowski, M., Docherty, S., \& Emden, C. (1997) "Qualitative metasynthesis: issues and techniques”, Research in Nursing and Health, Vol. 20, pp. 365-371.

Schein, E.H. (1985) Organizational culture and leadership. San Francisco, Jossey Bass.

Scott, T., Mannion, R., Davies, H.T.O. \& Marshall, M.N. (2003a) Healthcare performance and organisational culture. Oxon, Radcliffe Medical Press.

Scott, T., Mannion R., Davies, H.T.O. \& Marshall, M.N. (2003b) "Implementing culture change in healthcare: theory and practice", International Journal of Quality in Healthcare, Vol. 15, pp. 111-18.

Scott, T., Mannion, R., Marshall, M. \& Davies H.T.O. (2003c) "Does organisational culture influence health care performance? a review of the evidence", Journal of Health Services Research and Policy, Vol. 8 No. 2, pp. 105-17.

Scott, T., Mannion, R., Davies, H.T.O. \& Marshall, M. (2003d) "The quantitative measurement of organizational culture in healthcare: a review of the available instruments”, Health Services Research, Vol. 38 No. 3, pp. 923-45.

Shaw, R., Booth, A., Sutton, A., Miller, T., Smith, J., Young, B., Jones, D. \& DixonWoods, M. (2004) "Finding qualitative research: an evaluation of search strategies”, BMC Medical Research Methodology, Vol. 4 No. 5. 
Shortell, S.M., Jones, R.H., Rademaker, A.W., Gillies, R.R., Dranove, D.S., Hughes, E.F., Budetti, P.P., Reynolds, K.S. \& Huang, C.F. (2000) “Assessing the impact of total quality management and organizational culture on multiple outcomes of care for coronary artery bypass graft surgery patients”, Medical Care, Vol. 38 No. 2, pp. 202-17.

Smith, M.A., \& Webster, D.M. (2009) “Using Culture and Climate to Optimize Care”, Family Medicine, Vol. 41 No. 3, pp. 208-9.

Wilson, A. (2000) "The changing nature of primary health care teams and interprofessional relationships”. In P. Tovey (Ed.), Contemporary primary care: the challenges of change. Buckingham: OUP.

\section{Appendix A: 16 synthesis papers}

Paper 1: Blue, I. \& Fitzgerald, M. (2002) "Interprofessional relations: case studies of working relationships between registered nurses and general practitioners in rural Australia”, Journal of Clinical Nursing, Vol. 11 No. 3, pp. 314-321.

Paper 2: Brown, J.B., Lewis, L., Ellis, K., Stewart, M., Freeman, T.R. \& Kasperski, M.J. (2009) "Mechanisms for communicating within primary healthcare teams", Canadian Family Physician, Vol. 55 No. 12, pp. 1216-22.

Paper 3: Charles-Jones, H., Latimer, J. \& May, C. (2003) "Transforming primary care: the redistribution of medical work in primary care”, Sociology of Health and Illness, Vol. 25 No. 1, pp. 71-92.

Paper 4: Chesluk, B. \& Holmboe, E. (2010) "How teams work - or don't - in primary care: a field study on internal medicine practices", Health Affairs, Vol. 29 No. 5, pp. 874-9.

Paper 5: Elston, S. \& Holloway, I. (2001) "The impact of recent primary care reforms in the UK on interprofessional working in primary care centers", Journal of Interprofessional Care, Vol. 15 No. 1, pp. 19-27.

Paper 6: Grant, S., Huby, G., Watkins, F., Checkland, K., McDonald, R., Davies, H.T.O. \& Guthrie, B. (2009) "The impact of pay-for-performance on professional boundaries in UK primary care: an ethnographic study”, Sociology of Health and Illness, Vol. 31 No. 2, pp. 229-245.

Paper 7: Grumbach, K. \& Bodenheimer, T. (2004) “Can healthcare teams improve primary care practice?”, Journal of the American Medical Association, Vol. 291 No. 10, pp. 1246-1251.

Paper 8: Huby, G., Guthrie, B., Grant, S., Watkins, F., Checkland, K., McDonald, R. \& Davies, H.T.O. (2008) "Whither British general practice after the 2004 GMS contract? Stories and realities of change in four UK general practices”, Journal of Health Organisation and Management, Vol. 22 No. 1, pp. 63-78. 
Paper 9: Jenkins-Clarke, S., Carr-Hill, R. \& Dixon, P. (1998) "Teams and seams: skill mix in primary care”, Journal of Advanced Nursing, Vol. 28 No. 5, pp. 11201126.

Paper 10: Long, S. (1996) "Primary healthcare team workshop: team members' perspectives”, Journal of Advanced Nursing, Vol. 23 No. 5, pp. 935-941.

Paper 11: Miller, W.L., McDaniel, R.R., Crabtree, B.F. \& Stange, K.C. (2001) "Practice jazz: understanding variation in family practices using complexity science”, Journal of Family Practice, Vol. 50 No. 10, pp. 872-8.

Paper 12: Oandasan, I., Conn, L. \& Lingard, L. (2009) “The impact of space and time on interprofessional teamwork in Canadian primary healthcare settings: implications for healthcare reform”, Primary Healthcare Research and Development, Vol. 10 No. 2, pp. 151-62.

Paper 13: Pullon, S. (2008) "Competence, respect and trust: key features of successful interprofessional nurse-doctor relationships”, Journal of Interprofessional Care, Vol. 22 No. 2, pp. 133-147.

Paper 14: Pullon, S., McKinlay, E. \& Dew, K. (2009) "Primary healthcare in New Zealand: the impact of organisational factors on teamwork", British Journal of Primary care, Vol. 59 No. 560, pp. 191-197.

Paper 15: Shaw, A., de Lusignan, S. \& Rowlands, G. (2005) "Do primary care professionals work as a team: a qualitative study", Journal of Interprofessional Care, Vol. 19 No. 4, pp. 396-405.

Paper 16: Wiener-Ogilvie, S., Huby, G., Pinnock, H., Gillies, J. \& Sheikh, A. (2008) "Practice organisational characteristics can impact on compliance with the BTS/SIGN asthma guideline: qualitative comparative case study in primary care”, BMC Family Practice, Vol. 9 No. 32. 